\title{
EFFECT OF CASTING SPEED AND SUPERHEAT TEMPERATURE ON TEMPERATURE DISTRIBUTION FOR THE BILLET SURFACE IN THE CONTINUOUS CASTING PROCESS
}

\author{
${ }^{1}$ Paweł DROŻDŻ, ${ }^{1}$ Marcin RYWOTYCKI, ${ }^{1}$ Katarzyna MlŁKOWSKA- \\ PISZCZEK, ${ }^{2}$ Paweł KRAJEWSKI, ${ }^{2}$ Piotr PRZEGRAŁEK \\ ${ }^{1}$ AGH University of Science and Technology, Faculty of Metals Engineering and Industrial Computer \\ Science, Cracow, Poland, EU, pdrozdz@agh.edu.pl \\ ${ }^{2}$ ArcelorMittal Poland S.A, Dąbrowa Górnicza, Poland, EU, pawel.krajewski@arcelormittal.com \\ https://doi.org/10.37904/metal.2019.789
}

\begin{abstract}
The steel casting temperature is defined as liquidus temperature plus the superheat temperature. In practice, it is the temperature measured in the tundish during the continuous casting of steel. Together with the casting speed and water settings in the secondary cooling, they are key process parameters of continuous steel casting, and have a decisive impact on the quality of cast strands. An increase in the casting speed causes an increase in the strand temperature during continuous casting [1-4]. The paper analyses the impact of two casting speeds on the cast billet surface temperature for the selected strands of a continuous steel casting machine. The experiments were carried out in the industrial conditions at ArcelorMittal Poland S.A. Dąbrowa Górnicza at a six-strand machine for billet casting. When casting a sequence comprising five heats of a high carbon steel grade, dimensions $160 \times 160 \mathrm{~mm}$, the temperature was continuously measured with two optical pyrometers. One measurement point was located within the secondary cooling chamber, whereas the other one was immediately after the exit of the strand from the chamber. Additionally, during casting, the temperature was measured on the selected caster strands with a thermographic camera. This paper will present conclusions on the performed measurements of the cast strand surface temperature. Determining a reliable and accurate impact of the superheat temperature on the strand surface temperature was possible thanks to the capacity of the steel ladle, which exceeded $300 \mathrm{t}$.
\end{abstract}

Keywords: Continuous casting, high carbon steel, temperature measurement, casting speed

\section{INTRODUCTION}

The following parameters of the continuous steel casting process influence the process stability and the quality of the strands cast: steel superheat in the tundish, casting speed, and the cooling intensity within the primary and secondary cooling zones. These parameters directly influence the efficiency and stability of the continuous casting machine operation, as well as the cast strand quality [5-8]. The most important qualitative parameters of cast strands include: internal structure of cast strands (including micro and macrostructure, the equiaxed zone size), the surface quality, and cast strand geometry. The surface temperature of the strand cast is a measurable value indicating the impact of superheat, casting speed and the water quantity in the primary and secondary cooling [9-10]. The aim of the research is analysing the impact of casting speeds and superheat temperature on the cast billet surface temperature for the selected strands of a continuous steel casting machine. The most frequently used methods of cast strand surface temperature measurement include measurement with pyrometers placed in the secondary cooling chamber and with pyrometers and thermographic cameras at the secondary cooling chamber outlet. The temperature measurement of the cast strand surface and recording process parameters with e.g. ibaAnalyzer $\circledast$ are essential for the control and optimisation of the steel continuous casting process.

\section{STEEL SUPERHEAT TEMPERATURE}

The superheat temperature for any continuous casting machine is adjusted individually. This parameter depends on the steel chemical composition, heat casting time, risk of leaks during casting, tendency to SEN 
clogging, liquid steel temperature drops in the tundish, and qualitative results in cast strands. Bearing in mind the quality of the cast strand and the correct, disturbance free casting process, the continuous casting technology requires that the tundish temperature is higher by $20-30{ }^{\circ} \mathrm{C}$ than the liquidus temperature of a specific steel grade. An increase in the casting temperature by $10{ }^{\circ} \mathrm{C}$ involves a change in the steel solidification conditions and reduces the shell thickness at the mould outlet by about $1 \mathrm{~mm}$. In an extreme case this may lead to a shell break-out and liquid core leaks. Too high a casting temperature is undesirable, and its impact is most noticeable in the columnar zone. This zone can reach the strand axis when a strand with a small cross-section area is cast, and the superheating degree is high. A wide columnar zone is detrimental to mechanical properties, it contributes to the axial segregation of impurities and alloy elements, and to the axial porosity. Therefore, the steel cast at a continuous casting machine should have a temperature high enough to ensure a proper flow control, and at the same time the temperature should be low enough to ensure stable casting conditions and a good quality of the strand.

\section{THE IMPACT OF CASTING SPEED ON THE CHANGE OF PARAMETERS OF THE CASTING PROCESS}

Continuous steel casting process parameters during casting billets on strand no. 1 of the CC machine at ArcelorMittal Poland, Dąbrowa Górnicza, were reviewed. Special attention was paid to the last 2 heats in the sequence, they were cast at a speed of 1.8 and $2.5 \mathrm{~m} \mathrm{~min}^{-1}$. Heat 1 was made at 2:26 - 4:13 PM, and heat 2 at 4:20 - 6:34 PM. In order to obtain a more accurate image of the temperature distribution map on the strand surface along the whole metallurgical length, the continuous steel casting machine was additionally fitted with two measuring stands using optical pyrometers. Pyrometer P1 was installed between the two last rows of cooling nozzles within the secondary cooling zone, whereas pyrometer P2 was placed after leaving the secondary cooling chamber by the strand. The pyrometer locations were not changed during the measurements. The measurements were continuously recorded at every 1 second intervals during the casting of all heats. Table 1 presents a summary of actual casting parameters of 2 heats at the CC machine at ArcelorMittal Poland, Dąbrowa Górnicza, during stabilised casting conditions. The presented parameters are characterised by stable values during casting a whole heat.

Table 1 Summary of actual casting parameters of 2 heats at the CC machine at ArcelorMittal Poland, Dąbrowa Górnicza, during stabilised casting conditions for strand no. 1.

\begin{tabular}{|l|c|c|c|c|c|c|}
\hline \multicolumn{1}{|c|}{ Heat no. } & \multicolumn{3}{c|}{1} & \multicolumn{3}{c|}{$\mathbf{2}$} \\
\hline \multicolumn{1}{|c|}{ Signal } & Min & Max & Mean & Min & Max & Mean \\
\hline Casting speed $\left(\mathrm{m} \mathrm{min}^{-1}\right)$ & 1.7 & 1.9 & 1.8 & 2.4 & 2.6 & 2.5 \\
\hline Net weight in the tundish $(\mathrm{Mg})$ & 29.69 & 33.81 & 31.08 & 30.06 & 33.65 & 31.94 \\
\hline Continuous measurement of the tundish temperature $\left({ }^{\circ} \mathrm{C}\right)$ & 1487 & 1515 & 1506 & 1495 & 1522 & 1513 \\
\hline Current level in the mould $(\%)$ & 71.85 & 77.65 & 75.02 & 72.00 & 77.48 & 75.02 \\
\hline Output water temperature in the mould $\left({ }^{\circ} \mathrm{C}\right)$ & 46.60 & 47.20 & 46.92 & 47.70 & 49.00 & 48.48 \\
\hline Water temperature delta in the mould $\left({ }^{\circ} \mathrm{C}\right)$ & 7.50 & 8.30 & 7.80 & 9.40 & 10.70 & 10.04 \\
\hline Water flow rate through the mould $\left(\mathrm{I} \mathrm{min}^{-1}\right)$ & 1826 & 1847 & 1836 & 1824 & 1847 & 1836 \\
\hline Cooling water flow rate within the secondary cooling zone $\left(I \mathrm{~min}^{-1}\right)$ & 776 & 796 & 782 & 1050 & 1071 & 1061 \\
\hline Strand surface temperature Pyrometer P1 $\left({ }^{\circ} \mathrm{C}\right)$ & 943 & 954 & 950 & 916 & 935 & 927 \\
\hline Strand surface temperature Pyrometer P2 $\left({ }^{\circ} \mathrm{C}\right)$ & 885 & 910 & 904 & 926 & 951 & 943 \\
\hline Strand surface temperature $\mathrm{K} 1\left({ }^{\circ} \mathrm{C}\right)$ & 877 & 893 & 885 & 907 & 946 & 923 \\
\hline
\end{tabular}


Figure 1 presents the casting speed and temperature impacts on the surface temperature of the cast strand. The casting temperature was determined with a continuous measurement of liquid steel in the tundish. Casting a heat during about 2 hours causes its temperature to drop by about $28{ }^{\circ} \mathrm{C}$. As a result of the conducted analysis of measurements of the cast strand surface temperature with pyrometers $\mathrm{P} 1$ and P2, no significant changes in the surface temperature as a result of the heat temperature drop were observed. An increase in the casting speed caused a proportional increase in the cooling intensity, which lead to a decline in the surface temperature of the cast strand in the secondary cooling chamber, whereas its temperature after leaving the chamber increased compared to the temperature before the speed change. Another test point was located at a distance of $16 \mathrm{~m}$ to the liquid steel meniscus in the mould. This measurement was made with a thermographic camera.

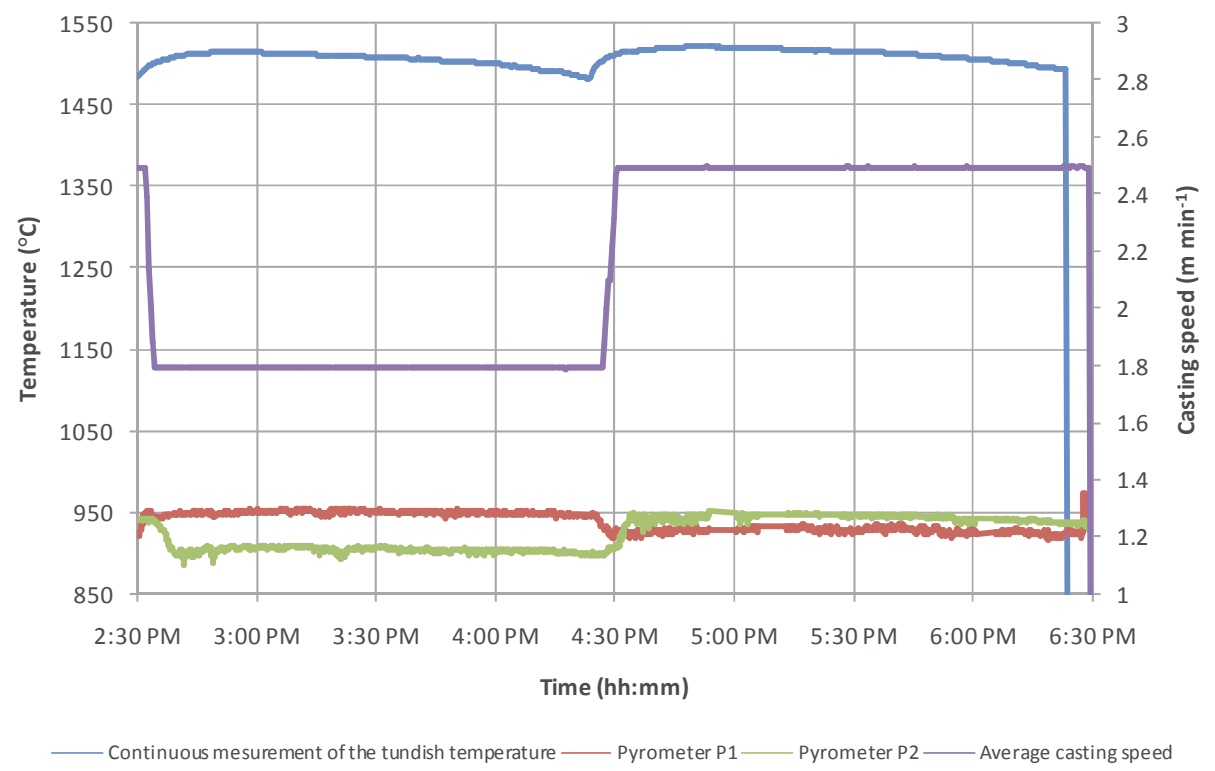

Figure 1 Impact of the casting speed and temperature on the surface temperature of the cast strand

During the measurements performed with a thermographic camera a series of thermograms were made. In order to achieve a better analysis of the impact of the casting speed change on the strand surface temperature, the temperature distribution results were summarised for strand 1 (Figures 2-3). An increase in the casting speed, which occurred for strand 1, results in an increase in the surface temperature (Figure 4). It is caused by a shorter heat transfer time in the cooling zones - primary and secondary. A change in the casting speed from 1.8 to $2.5 \mathrm{~m} \mathrm{~min}^{-1}$ in the case investigated, results in an increase in the surface temperature by about $40^{\circ} \mathrm{C}$ (Figure 5).
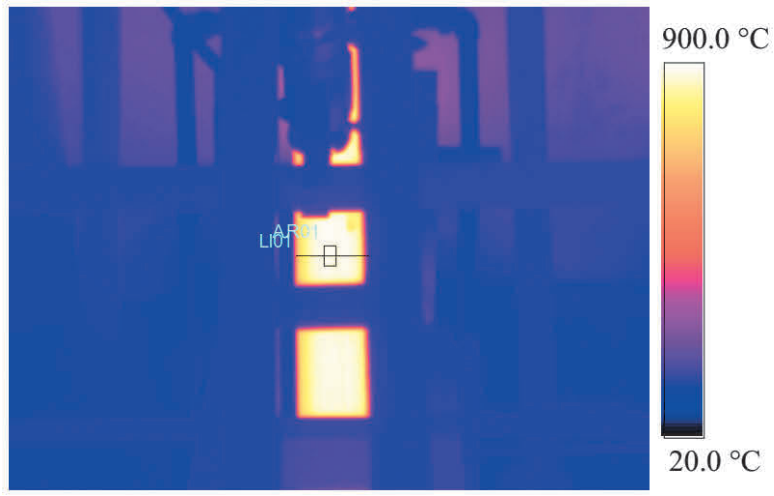

Figure 2 Thermogram for $v=1.8 \mathrm{~m} \mathrm{~min}^{-1}$

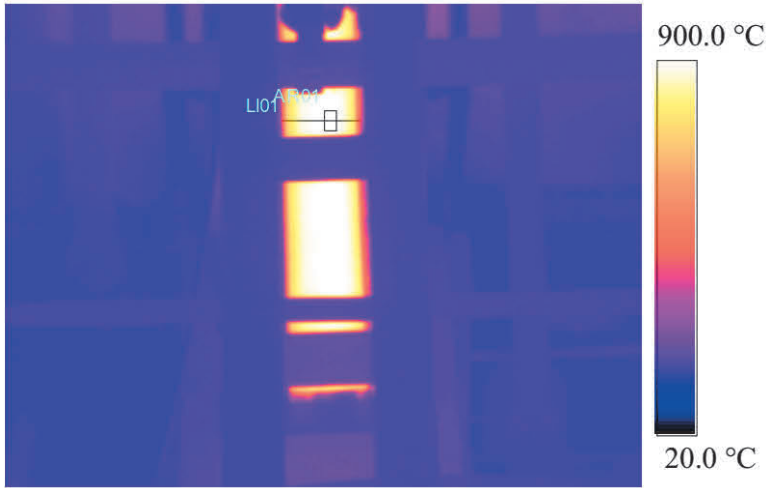

Figure 3 Thermogram for $v=2.5 \mathrm{~m} \mathrm{~min}^{-1}$ 


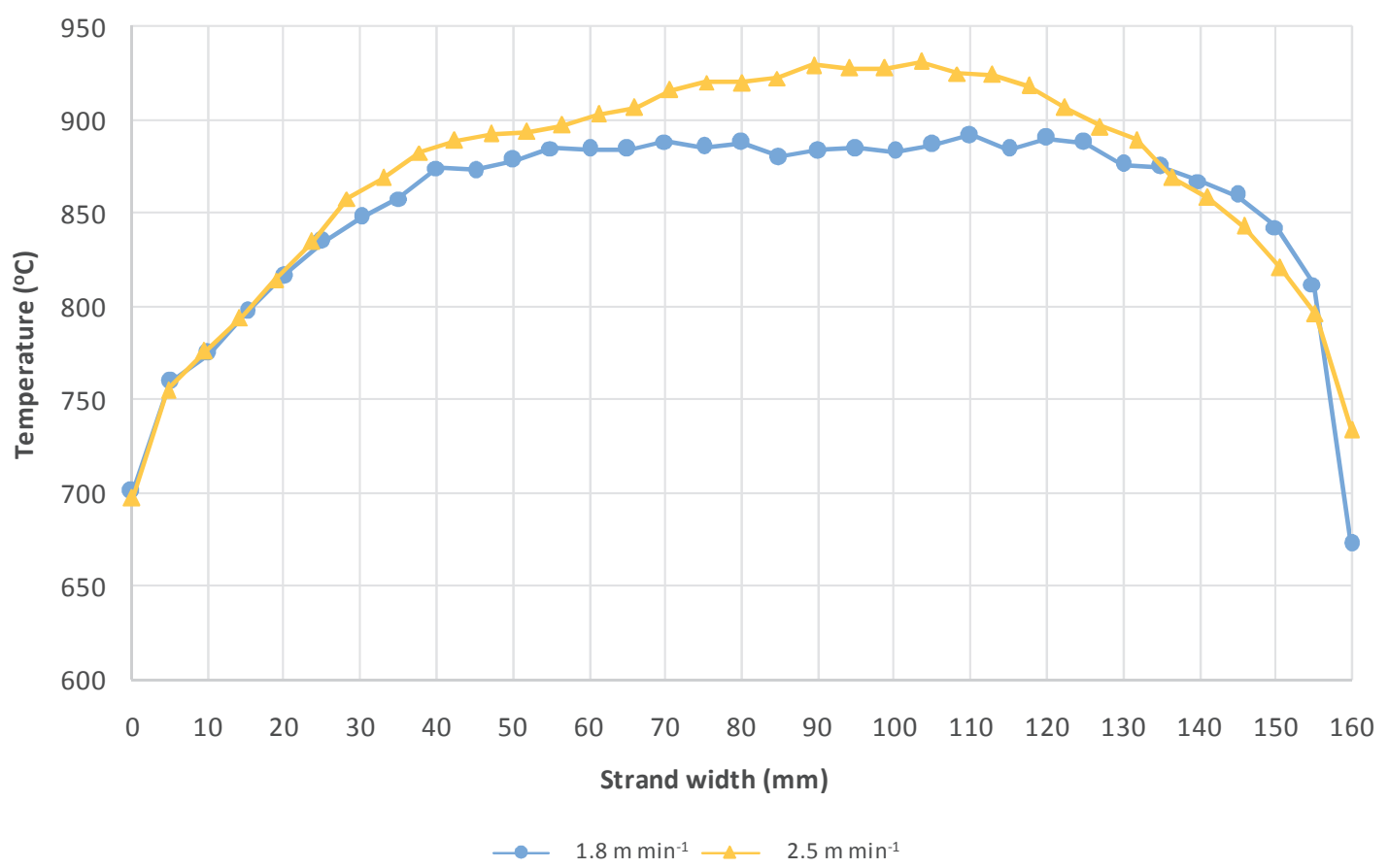

Figure 4 Strand surface temperature distribution for various casting speeds

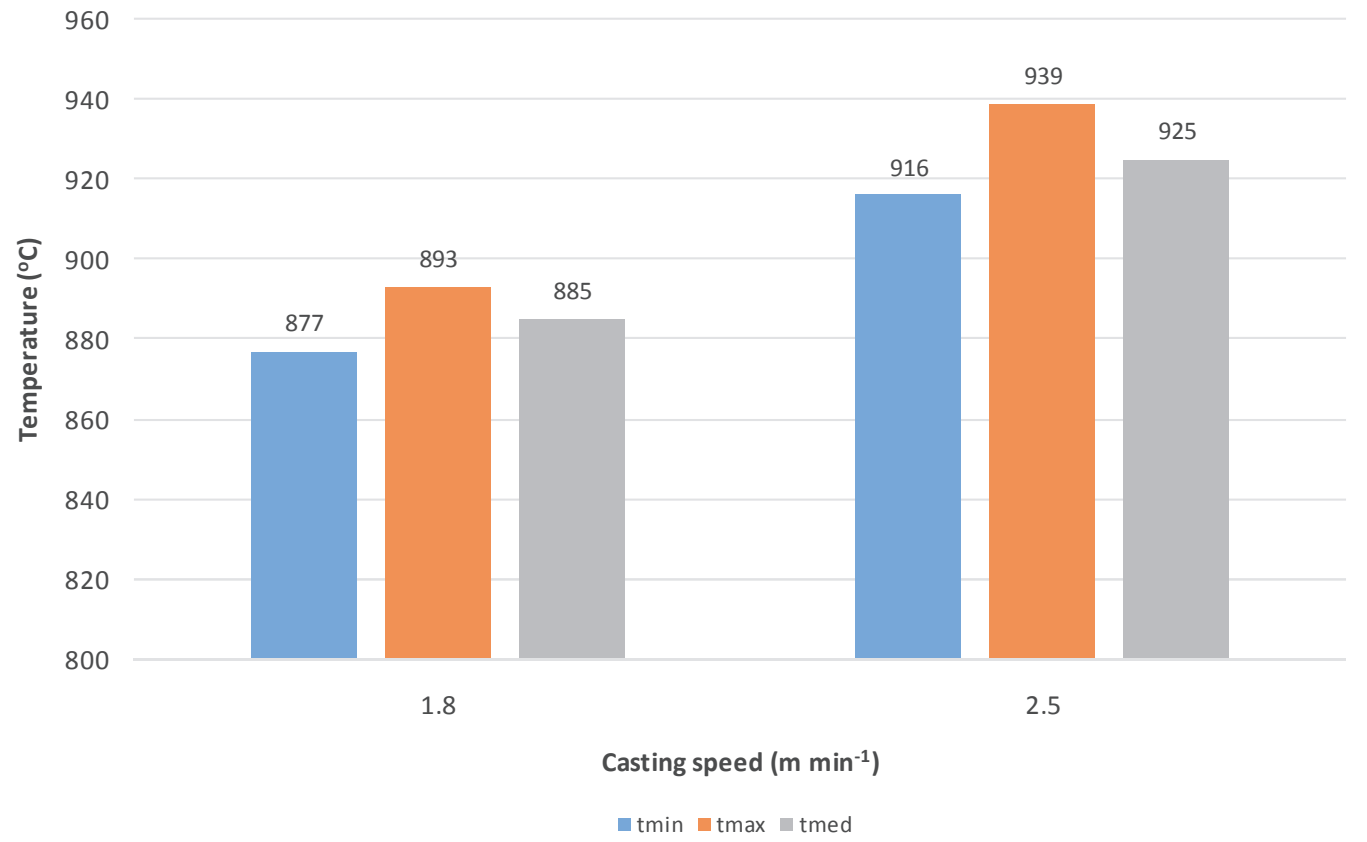

Figure 5 Minimum, maximum and medium temperatures in the axis of the strand top face for a selected strand top face fragment for strand 1, (area AR01)

\section{CONCLUSION}

As a result of the conducted analysis, taking into account the measurements of the cast strand surface temperature with pyrometers and a thermographic camera, the influence of key parameters of the continuous steel casting process on strand casting stability was established. The prepared graphs allow the strand surface 
temperature change for strand 1 of the CC machine operating at ArcelorMittal Poland, Dąbrowa Górnicza, to be analysed as a function of distance to the metal level in the mould as a consequence of a change in the casting temperature and casting speed. Changes in the recorded values of strand surface temperature, allow the impact of the cooling rate and intensity on the final product properties to be further tested. A decline in the casting temperature as a consequence of the heat cooling during its casting by about $28^{\circ} \mathrm{C}$ does not explicitly involve a decline in the strand surface temperature. A change in the casting speed from 1.8 to $2.5 \mathrm{~m} \mathrm{~min}^{-1}$ for the heats analysed results in a strand surface temperature decline by about $23^{\circ} \mathrm{C}$ for pyrometer $\mathrm{P} 1$, and an increase in the surface temperature by about $40^{\circ} \mathrm{C}$ for pyrometer $\mathrm{P} 2$, and the area where measurements were made with a thermographic camera. An increase in the casting speed results in a proportional increase in the cooling intensity in individual cooling zones, and consequently also a faster cooling on the surface of a strand still present in the secondary cooling zone. Strand surface pyrometer measurements after leaving the secondary cooling chamber show lower values. During stabilised casting conditions, all continuous casting process parameters feature readings similar to their mean values.

\section{ACKNOWLEDGEMENTS}

This research work was completed as part of project INNOSTAL in collaboration with the National Centre for Research and Development, Project No.: POIR.01.02.00-00-0219/17 and was financed through founds at AGH University of Science and Technology 5.72.110.629.

\section{REFERENCES}

[1] THOMAS, Brian G. Modeling of the Continuous Casting of Steel- Past, Present and Future. In ISS: Electric Furnace Conference Proceedings. 2001. vol. 59, pp. 3-30.

[2] KUDLIŃSKI, Zdzisław. Technologie odlewania stali. Wydawnictwo Politechniki Śląskiej. Gliwice, 2006.

[3] The Making, Shaping and Treating of Steel - Casting Volume CD, The AISE Steel Foundation, 2003.

[4] THOMAS, Brian G., LIU, Rui, and RIETOW, Bret. Combining Models and Measurements to Better Understand Steel Continuous Casting. In ECCC2014: 8th European Continuous Casting Conference. Graz: 2014, pp. 11301139.

[5] RAPPAZ, Michel, and GANDIN, Charles-Andre. Probabilistic modeling of microstructure formation in solidification process. Acta Metallurgica et Materialia. 1993. vol. 41, no. 2, pp. 345-360.

[6] HURTUK, Donald J., and Tzavaras, Alexander A. Solidification Structures and Continuous Casting of Steel Revisited, The Journal of The Minerals, Metals \& Materials Society, 1982. vol. 34, no. 2, pp. 40-45.

[7] BAI, Liang, WANG, Bo, ZHONG, Honggang, NI, Jie, ZHAI, Qijie, and ZHANG, Jieyu. Experimental and Numerical Simulations of the Solidification Process in Continuous Casting of Slab. Metals. 2016. vol. 6, pp. 53-65.

[8] DROŻDŻ, Paweł. Influence of cooling conditions on a slab's chill zone formation during continuous casting of steel. Archives of Metallurgy and Materials. 2017. vol. 62, no. 2A, pp. 911-918.

[9] HUGHES-NARBOROUGH, Peter. Dynamic Superheat determination in the continuous casting of steel. In COS2018: VIII International Conference on Continuous Casting Of Steel. Technology, Modelling, Defects of CCS ingots, Quality requirements. Krynica: 2018.

[10] RYWOTYCKI, Marcin, MIŁKOWSKA-PISZCZEK, Katarzyna, and TRĘBACZ, Lechosław. Identification of the boundary conditions in the continuous casting of steel. Archives of Metallurgy and Materials. 2012. vol. 57, no. 1, pp. 385-393. 